Conclusion Type I HCV is the most common hepatitis $\mathrm{C}$ virus type in our hemodialysis unit and in Turkey, so this low prevalence of criyoglobulinemia may be associated with the genotype of $\mathrm{HCV}$ and the differences of the geographic areas.

\section{FRI0153 CARDIOVASCULAR AUTONOMIC FUNCTIONS AND SYMPATHETIC SKIN RESPONSES IN BEHÇET'S DISEASE}

K Aksu, Z Colakoglu, G Keser, N Kýglýoglu, V Inal, G Gumusdýs, E Doganavsargýl. Rheumatology, Ege University Faculty of Medicine, Izmir, Turkey

\subsection{6/annrheumdis-2001.213}

Background Unlike other systemic necrotizing vasculitides, such as periarteritis nodosa and Churg-Strauss Syndrome, peripheral and autonomic nervous system involvement is rare Behçet's disease.

Objectives We examined the peripheral nervous system involvement, cardiovascular autonomic functions and sympathetic skin responses in Behçet's patients.

Methods Fifteen age and sex matched healthy controls, besides 26 Behçet's patients were included in this study. In order to exclude the effects of colchicine an the parameters tested, 16 patients with familial mediterranean fever (FMF) were also studied. In addition to electromyographic studies and sympathetic skin potentials, variations of R-R interval in electrocardiograhpy in response to hyperventilation and Valsalva manoeuvre were recorded. Patients with disorders that may cause autonomic dysfunction were excluded from the study.

Results There was no difference among the three groups in evaluations performed during hyperventilation and Valsalva manoeuvres. No pathologic electromyographic finding was recorded except the sensory motor polyneuropathy detected in a single Behçet's patient. The amplitude and latencies of skin potentials obtained in Behcet's patients were not significantly different when compared with healthy controls and FMF patients. Colchicine usage did not significantly alter the electrophysiological measurements in Behcet's and FMF patients.

Conclusion There was no evidence of peripheral autonomic nervous system involvement in Behçet's disease. We conclude that autonomic nervous system involvement is not significant in Behçet's disease.

\section{FRI0154 LEFLUNOMIDE IN A PATIENT WITH GLUCOCORTICOID- AND METHOTREXAT- RESISTANT TAKAYASU?S ARTERITIS}

${ }^{1} \mathrm{G}$ Haberhauer, ${ }^{1} \mathrm{~J}$ Feyertag, ${ }^{2} \mathrm{EM}$ Kittl, ${ }^{2} \mathrm{~K}$ Bauer, ${ }^{1} \mathrm{~A}$ Dunky. ${ }^{1} 5$ th Department of Internal Medicine (Rheumatology), Wilhelminen-Hospital; ${ }^{2}$ Central-Laboratory, Danube-Hospital, Vienna, Austria

10.1136/annrheumdis-2001.214

Background Takayasu's arteritis (TA) is a chronic inflammatory large-vessel vasculitis of unknown cause, which involves the aorta and its major branches. Glucocorticosteroids (GC) and methotrexat (MTX) are the primary treatment to reduce the activity of vascular inflammation in TA. A subset of TA patients $(<15 \%)$ has chronic, unremittive disease and is unresponsive to GC + MTX therapy. Herein we describe our benefit experience with Leflunomide (LEFLU) therapy in patient with GC- and MTX-resistant TA.
Objectives Case Report: A 28-year old Turkish female with (biopsy proved) TA, markedly elevated ESR of $96 \mathrm{~mm} / \mathrm{h}$, and elevated C-reactive protein (CRP) $73 \mathrm{mg} / \mathrm{dl}$ (normal

Postoperative, after 6 month, MTX therapy was withdrawn and replaced by LEFLU ( $30 \mathrm{mg} /$ day). Within the next 2 month GC was slowly tappered to $2 \mathrm{mg} /$ day and then withdrawn.

Six month after initiating LEFLU therapy, ESR $(22 \mathrm{~mm} / \mathrm{h})$, CRP $(12 \mathrm{mg} / \mathrm{dl})$, SAA $(8 \mathrm{mg} / \mathrm{dl})$ and IL-6 $(16 \mathrm{pg} / \mathrm{ml})$ significantly decreased near to normal ranges. Even sCD44v5 decreased to 9 $\mathrm{ng} / \mathrm{ml}$.

Blood pressure measurements were now $110 / 70 \mathrm{mmHg}$ in the right arm, 90/55 $\mathrm{mmHg}$ in the left arm and radial pulses were palpable in both arms. The patient reported no syncopes, headache or any limitations of activities of daily living. ESR, CRP, SAA, IL-6 and sCD44v5 still remained in the last mentioned low ranges during the next two month of observation.

Methods "*”"

Results “*”

Conclusion In this case of GC+MTX resistant TA, LEFLU appears to be an effective (slow acting) and well tolerated agent to reduce the activity of inflammation. Extensive and long-term studies will be required to assess our single observation.

\section{FRI0155 DIFFERENT SCHEMES OF CONSERVATIVE THERAPY IN PATIENTS WITH THROMBANGIITIS OBLITERANS}

MS Gurieva, AA Baranov, SV Bagrakova, PV Shiryaev, AA Kurdjukov. Internal Medicine, Medical Academy, Yaroslavl, Russia

10.1136/annrheumdis-2001.215

\section{Background}

Objectives To compare changes of the Birmingham vasculitis activity score (BVAS) and some laboratory parameters in thrombangiitis obliterans patients (pts) treated with antiplatelet agents and vasodilators in usual doses (first group) and with standard three-days scheme glucocorticoid and cyclophosphamide pulsetherapy (second group).

Methods The first group included 12 male (mean age $37.9 \pm$ 6.9 years) and the other one - 16 male (mean age $41.3 \pm 7.5$ years). Duration of disease and clinical symptoms before the treatment were comparable in both groups, excepting the frequency of joints pain $\left(\mathrm{n} 1=41.7 \%\right.$ v.s. $\mathrm{n}^{2}=6.3 \% ; \mathrm{p}<0.05$ ) and migratory superficial phlebitis $\left(\mathrm{n} 1=66.7 \%\right.$ v.s. $\mathrm{n}^{2}=$ $18.8 \% ; \mathrm{p}<0.05$ ), which were observed significantly more often in pts of the first group. Inspection of the pts was carried out before treatment and in a month. An estimation of clinical activity has carried out on BVAS. Serum levels of C-reactive protein (CRP) by ELISA and ESR at the same time were determinated as well.

Results Before the start of treatment there were no significant differences in values of BVAS (8.2 \pm 3.5 -first group; $8.4 \pm 3.2$ - second group), ESR and CRP between both groups. In a month BVAS was significantly lower in pts of the second group, then in the first one $(6.8 \pm 3.3$ - first group v.s. $3.9 \pm 1.7-$ second group; $\mathrm{p}<0.05)$. The mean values of CRP were not significantly changes during follow-up in both groups, but high serum levels of CRP were founded significantly more often in pts of the first group then in the second after the treatment $(\mathrm{n} 1=$ $58.3 \% ; \mathrm{n}^{2}=56.3 \%$ - before; $\mathrm{n} 1=66.7 \% ; \mathrm{n}^{2}=18.8 \% ; \mathrm{p}<$ 0.05 - after the treatment, respectively). The similar features were observed for the frequency of amputations ( $\mathrm{n} 1=58.33 \%$ v.s. $\left.\mathrm{n}^{2}=12.5 \% ; \mathrm{p}<0.05\right)$. 
Conclusion So, the pulse-therapy has more considerable antiinflammatory effect comparing to antiplatelet agents and vasodilators, therefore it is necessary to include it in the scheme of therapy pts with thrombangiitis obliterans.

\section{FRI0156 CYTOKINE RESPONSES TO STREPTOCOCCUS SANGUIS IN PATIENTS WITH BEHCET'S DISEASE}

${ }^{1} \mathrm{G}$ Mumcu, ${ }^{2} \mathrm{~T}$ Ergun, ${ }^{3} \mathrm{~N}$ Aritan, ${ }^{4} \mathrm{E}$ Eksioglu-Demiralp, ${ }^{3} \mathrm{H}$ Direskeneli. ${ }^{1}$ Health Education Faculty; ${ }^{2}$ Dermatology; ${ }^{3}$ Rheumatology; ${ }^{4}$ Immunology, Marmara University, Istanbul, Turkey

\subsection{6/annrheumdis-2001.216}

Background Atypical streptococcal infections (Streptoccocus Sanguis, Salivarius) are implicated in the pathogenesis of Behcet's Disease (BD), a systemic vasculitis of unknown aetiology.

Objectives This study aimed to investigate in mononuclear cell culture supernatants, in vitro cytokine responses to S. Sanguis in patients with BD compared to psoriasis (PS) and healthy controls (HC).

Methods Twelve patients with BD (4F/8M, mean age: 33.6 years), 7 with PS (4F/3M, mean age: 38.2 years) and $10 \mathrm{HC}$ (7F/3M, mean age: 27.5 years) were included in the study. IL-4, IL-10, and IFN- $\gamma$ responses were measured in peripheral blood mononuclear cell culture supernatants by ELISA after $48 \mathrm{~h}$ stimulations with S. Sanguis $(10 \mu \mathrm{g} / \mathrm{ml})$ and PHA $(20 \mu \mathrm{g} / \mathrm{ml})$. Positive responses were defined as above mean $+2 S D$ of unstimulated samples from HC.

Results Positive IL-10 responses to S. Sanguis were observed in 5/12 patients with BD (mean: $94 \mathrm{pg} / \mathrm{ml}$ ), 2/7 with PS (76 pg/ml), and $3 / 10$ with $\mathrm{HC}(57 \mathrm{pg} / \mathrm{ml})$. IFN- $\gamma$ responses were prominent both after S. Sanguis (BD: 4/12 positive, $31 \mathrm{pg} / \mathrm{ml}$; PS: 1/7 positive, $19 \mathrm{pg} / \mathrm{ml}$; HC: $1 / 10$ positive, $19 \mathrm{pg} / \mathrm{ml}$ ) and PHA (BD: 4/12 positive, $493 \mathrm{pg} / \mathrm{ml}$; PS: $1 / 7$ positive, $47 \mathrm{pg} / \mathrm{ml}$; HC: 0/10 positive, $10 \mathrm{pg} / \mathrm{ml}$ ). No IL-4 responses were observed in any group against both antigens.

Conclusion Although Th1 type cytokine responses are generally accepted to be dominant in $\mathrm{BD}$, in addition to IFN- $\gamma$, a prominent IL-10 response against S. Sanguis is observed in this study. These results suggest that a more complex cytokine profile is present in BD against microbial antigens.

\section{FRI0157 ANCA ANTIBODIES IN GRAVE'S BASEDOW DISEASE}

${ }^{1} \mathrm{M}$ Gumà, ${ }^{2} \mathrm{M}$ Juan, ${ }^{3} \mathrm{I}$ Salinas, ${ }^{1} \mathrm{E}$ Casado, ${ }^{1} \mathrm{~V}$ Ortiz-Santamaría, 'A Olivé. ${ }^{1}$ Rheumatology; ${ }^{2}$ Immunology, Hospital Universitari Germans Trias I Pujol, Badalona, Spain; ${ }^{3}$ Endocrinology

\subsection{6/annrheumdis-2001.217}

Background ANCA (anti-neutrophil cytoplasmic antibodies) are antibodies against specific proteins (proteinasa 3 and myeloperoxidase) and are present in the sera of patients having several underlying diseases).

Objectives To determine the frequency and specificity of ANCA in Grave's disease.

Methods Thirty-five serum of patients with Grave's Basedow disease were retrospectively examined. All patients were on treatment with anti-thyroid drugs at least for two months. ANCA antibodies were determined by indirect immunofluorescence. A ELISA test was performed to examine the presence of proteinasa 3 and myeolperoxidase (BL Diagnostica).

Results ANCA were positive in 60\% of patients with Grave's Basedow disease. Immunofluorescence patterns were as follow: 9
pANCA (26\%), 7 xANCA (20\%) and 5 cANCA (14\%). ELISA was positive in just one case (myeloperoxidase).

Conclusion ANCA antibodies are positive in Grave's Basedow disease. Anti-thyroid drugs may have a relationship with the presence of ANCA. Antigens are unknow.

\section{FRI0158 MICROSCOPIC HEMATURIA IN TEMPORAL ARTERITIS}

SM Vanderschueren, I Depoot, DC Knockaert, H Bobbaers. General Internal Medicine, University Hospital Gasthuisberg, Leuven, Belgium

\subsection{6/annrheumdis-2001.218}

Background Temporal arteritis (TA) is traditionally considered to spare the kidney, although an uncontrolled study reported microscopic hematuria in 10 out of 30 patients with TA. ${ }^{1}$

Objectives To study the incidence and characteristics of microscopic hematuria in TA.

Methods We studied retrospectively 41 patients with biopsyproved TA (the TA-patients), 41 patients with polymyalgia rheumatica (the PMR-patients) and 43 patients over 65 years of age admitted to the general internal medicine unit (the control patients). Urinalysis and urine microscopy were performed. Microscopic hematuria was defined as the presence of more than 5 red blood cells (RBCs) per high-power field. Patients with pyuria, significant bacteriuria or known urologic or nephrologic disorders were excluded.

Results Heem (trace or more) in the urine was present in $41.0 \%$ patients of the AT-patients, versus in $22.2 \%$ of the PMR-patients $(\mathrm{p}=0.14)$ and in $21.4 \%$ of the control patients $(\mathrm{p}=0.095)$. Microscopic hematuria was significantly more frequent in the AT-patients (Table 1). Presenting symptoms, renal function, arterial blood pressures, degree of proteinuria and of leucocyturia did not differ between AT-patients with and without microscopic hematuria. Urinary RBCs were predominantly dysmorphic in all 7 AT-patients in whom RBC-morphology was assessed. In 2 patients RBC-casts were present. Biopsy in one of them confirmed renal vasculitis. In $69.2 \%$ of the AT-patients microscopic hematuria disappeared after initiation of corticosteroid therapy.

\begin{tabular}{|c|c|c|c|c|}
\hline & -5 & $6-11$ & $>11$ & $\mathbf{p}^{*}$ \\
\hline AT-patients & 60.0 & 12.5 & 27.5 & - \\
\hline PMR-patients & 83.0 & 12.2 & 4.9 & .027 \\
\hline Control patients & 88.1 & 4.8 & 7.1 & .001 \\
\hline
\end{tabular}

${ }^{*}$ versus the AT-patients by Pearson chi-square.

Conclusion Microscopic hematuria of renal origin in TA is frequent but generally benign. Its presence, if unassociated with blood pressure elevation or renal function deterioration, serves to rule in rather than rule out the diagnosis of TA. In the typical setting invasive urologic and nephrologic work-up is not warranted.

\section{REFERENCE}

1 Manna R, Cristiano G, Todaro L, Latteri M, Gasbarinni G. Microscopic hematuria: a diagnostic aid in giant-cell arteritis? Lancet 1997;350:1226 